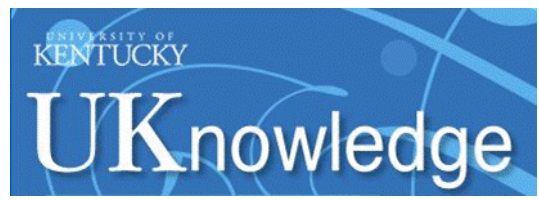

University of Kentucky

UKnowledge

9-1996

\title{
Rate Coefficients for Charge Transfer between Hydrogen and the First 30 Elements
}

\author{
J. B. Kingdon \\ University of Kentucky \\ Gary J. Ferland \\ University of Kentucky, gary@uky.edu
}

Follow this and additional works at: https://uknowledge.uky.edu/physastron_facpub

Part of the Astrophysics and Astronomy Commons, and the Physics Commons

Right click to open a feedback form in a new tab to let us know how this document benefits you.

\section{Repository Citation}

Kingdon, J. B. and Ferland, Gary J., "Rate Coefficients for Charge Transfer between Hydrogen and the First 30 Elements" (1996). Physics and Astronomy Faculty Publications. 150.

https://uknowledge.uky.edu/physastron_facpub/150

This Article is brought to you for free and open access by the Physics and Astronomy at UKnowledge. It has been accepted for inclusion in Physics and Astronomy Faculty Publications by an authorized administrator of UKnowledge. For more information, please contact UKnowledge@lsv.uky.edu. 


\section{Rate Coefficients for Charge Transfer between Hydrogen and the First 30}

Elements

Digital Object Identifier (DOI)
http://dx.doi.org/10.1086/192335

Notes/Citation Information

Published in The Astrophysical Journal Supplement Series, v. 106, p. 205-211.

(C) 1996. The American Astronomical Society. All rights reserved.

The copyright holder has granted permission for posting the article here. 
The Astrophysical Journal, Supplement Series, 106:205-211, 1996 September

(C) 1996. The American Astronomical Society. All rights reserved. Printed in U.S.A.

\title{
RATE COEFFICIENTS FOR CHARGE TRANSFER BETWEEN HYDROGEN AND THE FIRST 30 ELEMENTS
}

\author{
J. B. Kingdon ${ }^{1}$ AND G. J. FerLAND \\ Department of Physics and Astronomy, University of Kentucky, Lexington, KY 40506; \\ kingdon@cloud2.pa.uky.edu, gary@asta.pa.uky.edu \\ Received 1996 August 17; accepted 1996 February 7
}

\begin{abstract}
We present analytic fits to charge exchange rate coefficients over the full range of temperatures which occurs in photoionized or shock-heated plasmas. We consider reactions between neutral hydrogen and all elements with parent ion charge $q=1-4$ up to $Z=30$. Many rates were obtained from various sources in the literature. For reactions for which no data were available, we calculated rates using the Landau-Zener formalism. For these new reactions, we tabulate both total and state-specific rate coefficients. All are fitted with a consistent, accurate formula. These fits may be incorporated easily into spectral synthesis codes, and we make available an electronic form of our results. We draw attention to the most important reactions without high-quality rate coefficients to encourage further work.
\end{abstract}

Subject headings: atomic data - atomic processes

\section{INTRODUCTION}

Recent years have seen a rapid growth in the size of the astrophysical atomic database. Large undertakings such as the Opacity Project (Seaton 1987; Berrington et al. 1987) and the Iron Project (Hummer et al. 1993) will increase by several fold the amount of available data for photoionization, recombination, and collisional processes. In a recent paper, Verner \& Yakovlev (1995) computed analytic fits for photoionization cross sections for the ground-state shells of all ions through $Z=30$. While their calculations do not include the numerous resonances near threshold, they are generally in excellent agreement with experimental results at higher energies. In particular, they reproduce the highenergy tails, and recent extensions reproduce Opacity Project data near threshold (Verner et al. 1996). The fits allow these data to be incorporated into spectral synthesis codes with relative ease. These results should usher in advances in areas such as spectroscopic analysis and detailed modeling of astrophysical objects in the next few decades.

The aim of this paper is to generate a comparable set of charge transfer rate coefficients. Unfortunately, detailed quantal treatments are relatively difficult and rare (see Butler, Heil, \& Dalgarno 1980). However, one can obtain reasonably accurate results by use of the Landau-Zener (L-Z) approximation. L-Z rate coefficients have been computed for reactions between $\mathrm{H}$ and $\mathrm{He}$ and various ions (see Butler \& Dalgarno 1980a; Neufeld \& Dalgarno 1987; Swartz 1994; Kingdon, Ferland, \& Feibelman 1995; Kingdon 1995). A comparison between L-Z and quantal results by Butler \& Dalgarno (hereafter BD) shows reasonably good (within a factor of 3 ) agreement when the rates are large $\left(\sim 10^{-9} \mathrm{~cm}^{3} \mathrm{~s}^{-1}\right)$. The agreement is considerably poorer for smaller rates, but such reactions are generally unimportant.

Arnaud \& Rothenflug (1985, hereafter AR) published fits to charge transfer rates for several reactions between astrophysically important ions. In this paper, we extend that work to include analytic fits to charge exchange rate coeffi-

\footnotetext{
${ }^{1}$ Current address: Space Telescope Science Institute, 3700 San Martin Drive, Baltimore, MD 21218.
}

cients for all reactions between $\mathrm{H}$ and elements up to $Z=30$. Since highly charged ions will generally not coexist with $\mathrm{H}^{0}$ in most astrophysical environments, we restrict our calculations to parent ions with charge $q=1-4$. For those reactions for which no published data could be found, we have calculated rates using the $\mathrm{L}-\mathrm{Z}$ approximation.

We review briefly the L-Z method and the approach taken here in $\S 2$. We present our fitted rate coefficients and discuss these results in $\S 3$.

\section{METHOD}

We discuss the L-Z approximation and the important parameters below. Our approach is essentially that of BD, with some slight modifications as described in Kingdon (1995).

We consider reactions of the form $\mathrm{X}^{+n}+\mathrm{H} \rightarrow$ $\mathrm{X}^{+(n-1)}+\mathrm{H}^{+}+\Delta E$, where $\Delta E$ is the energy defect. Reactions with the arrow as written are referred to as charge transfer recombination, while the reverse process is called charge transfer ionization. For our calculations, both $\mathrm{H}$ and $\mathrm{X}^{+n}$ will be assumed to be in their ground states, while $\mathrm{X}^{+(n-1)}$ can, and usually will, be in an excited state.

The L-Z approximation states that the cross section for the above reaction at a given value $v$ of the radial component of the relative collision velocity is given by

$$
Q(v)=4 \pi R_{x}^{2} p_{0}(1+\lambda) \int_{1}^{\infty}\left(1-e^{-w x}\right) e^{-w x} x^{-3} d x,
$$

where

$$
w=\frac{\pi^{2}\left[\Delta U\left(R_{x}\right)\right]^{2}}{h v\left[d / d r\left(H_{11}-H_{22}\right)\right]_{R x}} .
$$

(We note that a minus sign was inadvertently left out of eq. [1] of Kingdon 1995 due to a typographical error. This had no effect on the results of that work.) Here $R_{x}$ is the point at which the incoming $\left(H_{11}\right)$ and outgoing $\left(H_{22}\right)$ diabatic potential curves intersect, $\Delta U$ is the energy separation of the adiabatic curves, $p_{0}$ is a probability, equal to the fraction of initial states that are also final states, and $\lambda=\left[H_{11}(\infty)\right.$ $\left.-H_{11}\left(R_{x}\right)\right] / E_{i}$, where $E_{i}$ is the energy. The rate coefficients are obtained by integrating equation (1) over a Maxwellian velocity distribution. The important parameters for the $\mathrm{L}-\mathrm{Z}$ 
method are $R_{x}, H_{11}, H_{22}$, and $\Delta U\left(R_{x}\right)$. We discuss the evaluation of these below.

The incoming potential $H_{11}$ can be approximated by

$$
H_{11}(R)=-61.25 Z^{2} R^{-4}+680.53 Z e^{-1.8 R} \mathrm{eV},
$$

where $Z$ is the charge on the reactant ion, and $R$ in this and the following equations is in units of bohrs. The first term in equation (3) represents the attraction due to the polarizability of the $\mathrm{H}$ nucleus, while the second term is due to the repulsive core. The outgoing potential is dominated by Coulomb repulsion and is given by

$$
H_{22}(R)=27.21(Z-1)\left(\frac{a_{0}}{R}\right)-\Delta E \mathrm{eV} .
$$

The determination of $\Delta U$ depends on whether the transfer can be classified as type I or II. In type I, there is a simple transfer of the $\mathrm{H} 1 s$ electron to the recombined ion. In this case, we take

$$
\Delta U_{\mathrm{I}}\left(R_{x}\right)=27.21 R_{x}^{2} e^{-R_{x}} \mathrm{eV} .
$$

Type II transfer involves the excitation of a core electron in the recombined ion in addition to the $1 s$ electron transfer. The effect reduces the interaction. Here

$$
\Delta U_{\mathrm{II}}\left(R_{x}\right)=\frac{1}{2} e^{-0.4 R_{x}} \Delta U_{\mathrm{I}}\left(R_{x}\right) \mathrm{eV} .
$$

Equations (3)-(6) are taken from BD. Finally, the value of the avoided crossing $R_{x}$ is derived from equating equations (3) and (4) and solving. This result can be approximated roughly by $R_{x}=27.21(n-1) / \Delta E$, where $\Delta E$ is in units of $\mathrm{eV}$.

\section{RESULTS}

\subsection{Previous Rates}

We have attempted whenever possible to use quantal results for these rate coefficients. We have conducted an extensive literature search using the CFADC bibliographic database at Oak Ridge National Laboratory. This database includes references from 1978 to the present. In cases in which older data were required, a manual search was conducted. The references for all rates are given in Table 1.

As discussed in $\S 1$, one of the primary goals of this paper is to provide a uniform set of fits to these data. For simplicity, we will use a single expression to fit all rates. To this end, we take the fitting function of AR, in which the recombination rate coefficient $\alpha_{\text {rec }}$ (in units of $\mathrm{cm}^{3} \mathrm{~s}^{-1}$ ) is given by the expression

$$
\alpha_{\mathrm{rec}}\left(t_{4}\right)=a t_{4}^{b}\left[1+c \exp \left(d t_{4}\right)\right],
$$

where $t_{4}$ is the temperature in units of $10^{4}$, and $a, b, c$, and $d$ are the parameters of the fit (with $a$ in units of $10^{-9} \mathrm{~cm}^{3}$ $\mathrm{s}^{-1}$ ).

We present the fits to the previously published charge transfer rates in Table 1. For all reactions, the rates given here are total rates. Column (1) gives the reactant (parent) ion, with the four fitting parameters listed in columns (2)(5). Column (6) gives the temperature range over which the data were fitted. We emphasize here that the fits to these data are only valid within the given temperature range; extrapolation significantly outside this range is not recommended. Finally, column (7) gives the source of the rate coefficients.

In cases in which there are many significant channels having the same molecular symmetry, adding up the rates for individual channels to obtain the total rate can result in an overestimate. Such reactions are noted in the table. When a reaction has no significant channels, it may proceed via radiative charge transfer. The rates for these cases have all been set to $1 \times 10^{-14}$ (see Butler, Guberman, \& Dalgarno 1977).

For some of the reactions listed in Table 1, fits have already been presented by AR, whose fitting function we have used here. For a few of these cases, we have found more accurate, up-to-date data in the literature than that used by AR. However, even for those cases in which we have used the same data, we find that modern optimization methods can provide significantly better fits. We plot in Figure 1 fits to the reaction $\mathrm{N}^{+2}+\mathrm{H} \rightarrow \mathrm{N}^{+}+\mathrm{H}^{+}$. The crosses represent the data from Butler et al. (1980), with the solid line the fit by AR to these points. The triangles are the data from Herrero et al. (1995a), with our fit to these data. This figure illustrates the accuracy of our fits, which in this case is quite good despite the large number of points and inflection of the curve. In addition, since both the Butler et al. (1980) data and the Herrero et al. (1995a) data were derived from quantal calculations, this figure serves also to illustrate the accuracy of charge transfer calculations in general.

A few reactions require some additional comments. We first consider the near-resonant reaction $\mathrm{O}^{+}+\mathrm{H} \rightleftharpoons \mathrm{O}$ $+\mathrm{H}^{+}$. Field \& Steigman (1971) calculated rate coefficients for these reactions from 10 to $10^{4} \mathrm{~K}$, using the orbiting approximation and assuming statistical redistribution of the atomic states. Chambaud et al. (1980) pointed out that these approximations result in an overestimate of the rate coefficients at low temperatures. Unfortunately, they calculate results only up to $1000 \mathrm{~K}$. Therefore, we have chosen to use the Chambaud et al. results up to $1000 \mathrm{~K}$ and the results of Field \& Steigman at $10^{4} \mathrm{~K}$. That this choice is reasonable can be seen from Table 4 of Chambaud et al., which compares the results of the two studies. The Chambaud et al. data approach asymptotically the Field \& Steigman results as the temperature increases, with an agreement of $\sim 35 \%$ at $1000 \mathrm{~K}$. In light of the above, the results for these reactions should be regarded with some uncertainty at high temperatures.

Secondly, the reactions $\mathrm{C}^{+}+\mathrm{H} \rightleftharpoons \mathrm{C}+\mathrm{H}^{+}$and $\mathrm{S}^{+}+\mathrm{H} \rightleftharpoons \mathrm{S}+\mathrm{H}^{+}$were calculated by Butler \& Dalgarno (1980b) at a temperature of $10,000 \mathrm{~K}$ only. The fits given in Table 1 were suggested by P. C. Stancil (1995, private communication). Both these reactions are strongly endothermic, and so the rate coefficients should fall off strongly with decreasing temperature. We have assumed simple radiative charge transfer for the reverse of both reactions. We emphasize that the data for these reactions are particularly uncertain and should be used with appropriate caution. Fortunately, the predicted rate coefficients are extremely small. We have included these data mainly for the sake of completeness.

\subsection{New Data}

For those reactions for which we could find no published rates at astrophysical temperatures, we have calculated L-Z recombination rate coefficients using the software by Bienstock (1983), which utilizes the methodology presented in $\S 2$. The rates were determined at four temperatures given by $\log T=3,3.5,4$, and 4.5 . We calculated rates for all significant channels in the recombined ion, ignoring fine 
TABLE 1

Charge Transfer Recombination Rates

\begin{tabular}{|c|c|c|c|c|c|c|}
\hline Ion & $\mathrm{a}\left(10^{-9} \mathrm{~cm}^{3} / \mathrm{s}\right)$ & $\mathbf{b}$ & c & d & Temp. Range $\left({ }^{\circ} \mathrm{K}\right)$ & Ref. \\
\hline $\mathrm{He}^{+}$ & $7.47(-6)$ & 2.06 & 9.93 & -3.89 & $6(3)-1(5)$ & 1 \\
\hline${ }^{a} \mathrm{He}^{+2}$ & $1.00(-5)$ & 0.00 & 0.00 & 0.00 & $\sim 1(3)-1(7)$ & 2 \\
\hline $\mathrm{Li}^{+2}$ & 1.26 & 0.96 & 3.02 & -0.65 & $1(3)-3(4)$ & 3 \\
\hline${ }^{a} \mathrm{Li}^{+3}$ & $1.00(-5)$ & 0.00 & 0.00 & 0.00 & $2(3)-5(4)$ & 4 \\
\hline${ }^{a} \mathrm{Be}^{+2}$ & $1.00(-5)$ & 0.00 & 0.00 & 0.00 & $2(3)-5(4)$ & 4 \\
\hline${ }^{a} \mathrm{Be}^{+3}$ & $1.00(-5)$ & 0.00 & 0.00 & 0.00 & $2(3)-5(4)$ & 4 \\
\hline $\mathrm{Be}^{+4}$ & 5.17 & 0.82 & -0.69 & -1.12 & $2(3)-5(4)$ & 4 \\
\hline $\mathrm{B}^{+2}$ & $2.00(-2)$ & 0.00 & 0.00 & 0.00 & $\gtrsim 1(3)$ & 3 \\
\hline${ }^{a} \mathrm{~B}^{+3}$ & $1.00(-5)$ & 0.00 & 0.00 & 0.00 & $2(3)-5(4)$ & 4 \\
\hline $\mathrm{B}^{+4}$ & $5.27(-1)$ & 0.76 & -0.63 & -1.17 & $2(3)-5(4)$ & 4 \\
\hline${ }^{b} \mathrm{C}^{+1}$ & $1.76(-9)$ & 8.33 & 4278.78 & -6.41 & $3(3)-1(4)$ & 5 \\
\hline $\mathrm{C}^{+2}$ & $1.67(-4)$ & 2.79 & 304.72 & -4.07 & $5(3)-5(4)$ & 6 \\
\hline $\mathrm{C}^{+3}$ & 3.25 & 0.21 & 0.19 & -3.29 & $1(3)-1(5)$ & 7 \\
\hline$C^{+4}$ & 332.46 & -0.11 & $-9.95(-1)$ & $-1.58(-3)$ & $1(1)-1(5)$ & 8 \\
\hline $\mathrm{N}^{+1}$ & $1.01(-3)$ & -0.29 & -0.92 & -8.38 & $1(2)-5(4)$ & 9 \\
\hline $\mathrm{N}^{+2}$ & $3.05(-1)$ & 0.60 & 2.65 & -0.93 & $1(3)-1(5)$ & 10 \\
\hline $\mathrm{N}^{+3}$ & 4.54 & 0.57 & -0.65 & -0.89 & $1(1)-1(5)$ & 8 \\
\hline $\mathrm{N}^{+4}$ & 3.28 & 0.52 & -0.52 & -0.19 & $1(3)-3(5)$ & 11 \\
\hline $\mathrm{O}^{+1}$ & 1.04 & $3.15(-2)$ & -0.61 & -9.73 & $1(1)-1(4)$ & 12,13 \\
\hline $\mathrm{O}^{+2}$ & 1.04 & 0.27 & 2.02 & -5.92 & $1(2)-1(5)$ & 14 \\
\hline $\mathrm{O}^{+3}$ & 3.98 & 0.26 & 0.56 & -2.62 & $1(3)-5(4)$ & 15 \\
\hline${ }^{c} \mathrm{O}^{+4}$ & $2.52(-1)$ & 0.63 & 2.08 & -4.16 & $1(3)-3(4)$ & 16 \\
\hline${ }^{a} \mathrm{~F}^{+2}$ & $1.00(-5)$ & 0.00 & 0.00 & 0.00 & $2(3)-5(4)$ & 4 \\
\hline$F^{+3}$ & 9.86 & 0.29 & -0.21 & -1.15 & $2(3)-5(4)$ & 4 \\
\hline $\mathrm{F}^{+4}$ & $7.15(-1)$ & 1.21 & -0.70 & -0.85 & $2(3)-5(4)$ & 4 \\
\hline${ }^{a} \mathrm{Ne}^{+2}$ & $1.00(-5)$ & 0.00 & 0.00 & 0.00 & $5(3)-5(4)$ & 6 \\
\hline $\mathrm{Ne}^{+3}$ & 14.73 & $4.52(-2)$ & -0.84 & -0.31 & $5(3)-5(4)$ & 6 \\
\hline $\mathrm{Ne}^{+4}$ & 6.47 & 0.54 & 3.59 & -5.22 & $1(3)-3(4)$ & 16 \\
\hline${ }^{a} \mathrm{Na}^{+2}$ & $1.00(-5)$ & 0.00 & 0.00 & 0.00 & $2(3)-5(4)$ & 4 \\
\hline $\mathrm{Na}^{+3}$ & 1.33 & 1.15 & 1.20 & -0.32 & $2(3)-5(4)$ & 4 \\
\hline $\mathrm{Na}^{+4}$ & $1.01(-1)$ & 1.34 & 10.05 & -6.41 & $2(3)-5(4)$ & 4 \\
\hline $\mathrm{Mg}^{+2}$ & $8.58(-5)$ & $2.49(-3)$ & $2.93(-2)$ & -4.33 & $1(3)-3(4)$ & 16 \\
\hline $\mathrm{Mg}^{+3}$ & 6.49 & 0.53 & 2.82 & -7.63 & $1(3)-3(4)$ & 16 \\
\hline $\mathrm{Mg}^{+4}$ & 6.36 & 0.55 & 3.86 & -5.19 & $1(3)-3(4)$ & 16 \\
\hline${ }^{a} \mathrm{Al}^{+2}$ & $1.00(-5)$ & 0.00 & 0.00 & 0.00 & $1(3)-3(4)$ & 17 \\
\hline $\mathrm{Al}^{+3}$ & $7.11(-5)$ & 4.12 & $1.72(4)$ & -22.24 & $1(3)-3(4)$ & 17 \\
\hline $\mathrm{Al}^{+4}$ & $7.52(-1)$ & 0.77 & 6.24 & -5.67 & $1(3)-3(4)$ & 17 \\
\hline $\mathrm{Si}^{+2}$ & 1.23 & 0.24 & 3.17 & $4.18(-3)$ & $1(1)-1(6)$ & 18 \\
\hline $\mathrm{Si}^{+3}$ & $4.90(-1)$ & $-8.74(-2)$ & -0.36 & -0.79 & $1(3)-3(4)$ & 16 \\
\hline $\mathrm{Si}^{+4}$ & 7.58 & 0.37 & 1.06 & -4.09 & $1(3)-5(4)$ & 19 \\
\hline${ }^{b} S^{+1}$ & $3.82(-7)$ & 11.10 & $2.57(4)$ & -8.22 & $3(3)-1(4)$ & 5 \\
\hline${ }^{a} S^{+2}$ & $1.00(-5)$ & 0.00 & 0.00 & 0.00 & $1(3)-3(4)$ & 16 \\
\hline $\mathrm{S}^{+3}$ & 2.29 & $4.02(-2)$ & 1.59 & -6.06 & $1(3)-3(4)$ & 16 \\
\hline${ }^{c} \mathrm{~S}^{+4}$ & 6.44 & 0.13 & 2.69 & -5.69 & $1(3)-3(4)$ & 16 \\
\hline${ }^{a} \mathrm{Ar}^{+2}$ & $1.00(-5)$ & 0.00 & 0.00 & 0.00 & $1(3)-3(4)$ & 16 \\
\hline $\mathrm{Ar}^{+3}$ & 4.57 & 0.27 & -0.18 & -1.57 & $1(3)-3(4)$ & 16 \\
\hline $\mathrm{Ar}^{+4}$ & 6.37 & 0.85 & 10.21 & -6.22 & $1(3)-3(4)$ & 16 \\
\hline $\mathrm{Ca}^{+3}$ & $3.17(-2)$ & 2.12 & 12.06 & -0.40 & $1(3)-3(4)$ & 17 \\
\hline $\mathrm{Ca}^{+4}$ & 2.68 & 0.69 & -0.68 & -4.47 & $1(3)-3(4)$ & 17 \\
\hline $\mathrm{Fe}^{+2}$ & 1.26 & $7.72(-2)$ & -0.41 & -7.31 & $1(3)-1(5)$ & 20 \\
\hline $\mathrm{Fe}^{+3}$ & 3.42 & 0.51 & -2.06 & -8.99 & $1(3)-1(5)$ & 21 \\
\hline $\mathrm{Ni}^{+2}$ & 1.05 & 1.28 & 6.54 & -1.81 & $1(3)-1(5)$ & 20 \\
\hline
\end{tabular}

NoTE-The notation $a(b)$ here means $a \times 10^{b}$.

" Radiative charge transfer may be the most rapid mechanism.

${ }^{b}$ Results are very uncertain; see text.

c Results may be overestimated due to several channels having the same symmetry.

REFERENCES.- (1) Zygelman et al. 1989; (2) West, Lane, \& Cohen 1982; (3) Dalgarno 1954; (4) Kingdon 1995; (5) Butler \& Dalgarno 1980b; (6) Butler et al. 1980; (7) Herrero et al. 1995b; (8) Gargaud et al. 1981; (9) Butler \& Dalgarno 1979; (10) Herrero et al. 1995a; (11) Stancil et al. 1995; (12) Field \& Steigman 1971; (13) Chambaud et al. 1980; (14) Honvault et al. 1995; (15) Gargaud, McCarroll, \& Opradolce 1989; (16) Butler \& Dalgarno 1980a; (17) Kingdon et al. 1995; (18) Gargaud, McCarroll, \& Valiron 1982; (19) P. C. Stancil 1995, private communication;(20) Neufeld \& Dalgarno 1987; (21) Neufeld 1984. 


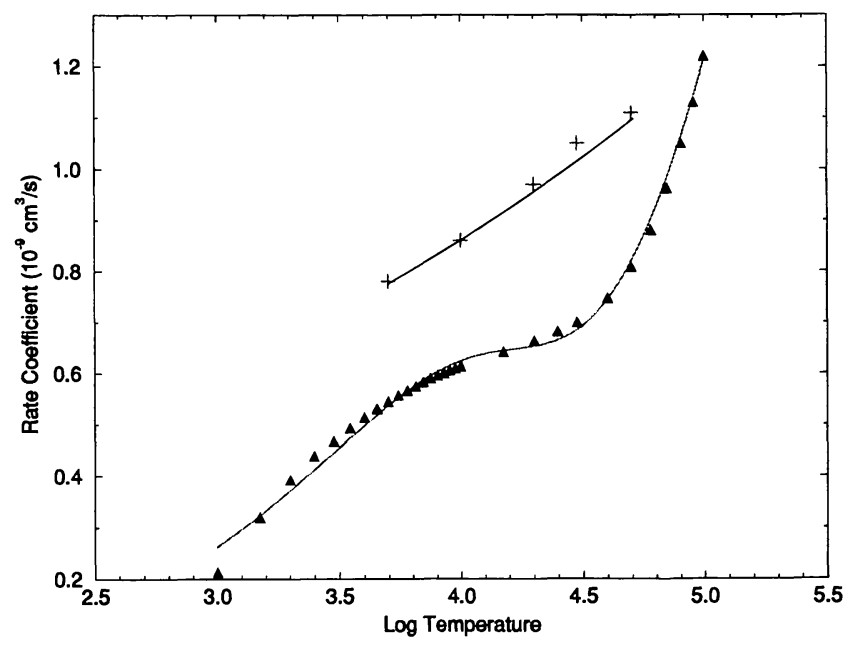

FIG. 1.-Comparison of fits to data for the reaction $\mathrm{N}^{+2}+\mathrm{H} \rightarrow \mathrm{N}^{+}+\mathrm{H}^{+}$. Crosses represent actual data points, taken from Butler et al. (1980), and solid line represents the fit of Arnaud \& Rothenflug (1985) to these points. We also show our fit to the more recent data of Herrero et al. (1995a), depicted as triangles.

structure. Since charge transfer recombination, unlike radiative or dielectronic recombination, populates specific levels of the recombined ion, these results are important for determining how a given line is affected by the charge transfer process. The total rate coefficients were then obtained simply by summing those for the individual channels.

We give the results of our fitting procedure for the rates determined here in Table 2. Column (1) gives the reactant ion, while column (2) gives the electron configuration of the reactant channel, or the work "Total" for the total rate coefficient. For brevity, we list only those channels for which the rate was greater than $10 \%$ of the total rate at least one of the four evaluated temperature points. For ions having more than one such channel, the rates are listed in order of increasing wavenumber. If there is only one appreciable channel, we list the configuration for reference, although the rate is actually the total rate. Next, we give the four fitting parameters in columns (3)-(6). Finally, column (7) lists the source used for energy levels in the recombined ion. Again, we caution against extrapolating the fit outside the temperature range given above.

As in Table 1, we note those reactions which occur by radiative charge transfer, as well as those in which the total may be overestimated due to many channels having the same symmetry. For reference, we also note those channels in which the reaction occurs by type II transfer as discussed in the previous section.

The ions $\mathrm{K}^{+4}, \mathrm{Mn}^{+4}, \mathrm{Zn}^{+3}$, and $\mathrm{Zn}^{+4}$ merit special attention. For the first two of these ions, the electron transfers into relatively high atomic levels, near the limit of published energy levels, but still well below the ionization limit. The rates for these ions are therefore smaller than might be expected. We believe that these smaller rates are due to a lack of determined energy levels at high energies. Thus, they should be considered as underestimates of the true rates and should be used with caution. For $\mathrm{Zn}^{+3}$ and $\mathrm{Zn}^{+4}$, we were unable to find reasonably complete tabulations of the appropriate energy levels. Therefore, these rates should also be considered as underestimates.

As mentioned in the introduction, charge transfer recombination normally results in a product ion that is in an excited state. In most astrophysical situations, the reverse reaction is negligible, since the excited states have small populations. However, for some reactions, the ground state can be a viable channel. In these instances, the reverse process of charge transfer ionization can be important. The reverse rate is related to the forward rate through detailed balance. This fact allows us to express the ionization rate coefficients as a product of the fitting function used above and the Boltzmann factor exp $(-\Delta E / k T)$. The results are given in Table 3. The first column gives the initial ion, the next five give the four fitting parameters, then the temperature range, as in Tables 1 and 2, and the last column gives the value $\Delta E / k$ (in units of $10^{4} \mathrm{~K}$ ). For all reactions, the reference is the same as that for the reverse recombination reaction listed in either Table 1 or 2 . Due to the additional Boltzmann factor, charge transfer ionization is generally unimportant except at high temperatures. We list also in Table 3 fits for ionization reactions involving $\mathrm{Li}$ and $\mathrm{Mg}$ with a proton, for which the forward reaction is negligible due to the energetics of the reactions. In these cases, we have simply set $\Delta E / k$ equal to zero and fitted the data directly.

Charge transfer recombination rate coefficients were fitted over the temperature range where this process can be important. A typical rate coefficient for radiative/ dielectronic recombination is on the order of $10^{-12} \mathrm{~cm}^{3}$ $\mathrm{s}^{-1}$, whereas a large charge transfer rate coefficient is on the order of $10^{-9} \mathrm{~cm}^{3} \mathrm{~s}^{-1}$. For these values, the ratio of the rates (in $\mathrm{s}^{-1}$ ) of charge transfer $(\mathrm{CT})$ to recombination $(\mathrm{Rec})$ is given by

$$
\frac{R_{\mathrm{CT}}}{R_{\mathrm{Rec}}}=\frac{\alpha_{\mathrm{CT}} \eta_{\mathrm{H}^{0}}}{\alpha_{\mathrm{Rec}} n_{e}} \simeq 10^{3} \frac{n_{\mathrm{H}^{0}}}{n_{e}} \simeq \frac{10^{3}}{1.2} \frac{n_{\mathrm{H}^{0}}}{n_{\mathrm{H}^{+}}},
$$

where the $\alpha$ values are the rate coefficients and the $n$ values are the densities of neutral $\mathrm{H}$ and electrons, respectively. For the last term in equation (8), we consider a plasma in which $\mathrm{He}$ is doubly ionized; in this case we have $n_{e} \approx 1.2 n_{p}$. Therefore, the rate of charge transfer recombination will be equal to or greater than the rate of radiative recombination provided that $n_{\mathrm{H}^{\circ}} / n_{\mathrm{H}^{+}}>0.0012$. Hydrogen must be more ionized than this for nebular temperatures above $35,000 \mathrm{~K}$ due to collisional ionization. For temperatures greater than this, there will be too little neutral $\mathrm{H}$, and regular recombination will dominate. For the reactions considered in this paper, all fits should be valid to at least this temperature.

For charge transfer ionization, the Boltzmann factor mentioned above and the dependence on the ionized $\mathrm{H}$ density results in a reverse of the situation for recombination; that is, charge transfer ionization will be important at higher temperatures. Of the astrophysically important ionization reactions listed in Table 3 , it is desirable to have calculations at higher temperatures for $\mathrm{N}^{0}, \mathrm{O}^{\mathbf{0}}$, and $\mathbf{M g}^{\mathbf{0}}$.

We note that for a few ions considered in this paper, reactions with $\mathrm{H}$ are endothermic. In these cases, the diabatic potential curves do not intersect, and no avoided crossing occurs. We list these reactions for convenience in Table 4, where column (1) gives the reactant ion and column (2) gives the energy defect $\Delta E$, taken to be negative for endothermic reactions. In some of these cases, $\Delta E$ is very small, so that the reactions are nearly resonant.

Finally, based on this work, we wish to point out several reactions with the fastest rate coefficients which should be examined further using quantal methods. These are (the 
TABLE 2

Charge Transfer Recombination Rates (New Results)

\begin{tabular}{|c|c|c|c|c|c|c|}
\hline Ion & Level & $\mathrm{a}\left(10^{-9} \mathrm{~cm}^{3} / \mathrm{s}\right)$ & b & c & d & Ref. \\
\hline$P^{+2}$ & $3 s^{2} 3 p^{2}{ }^{1} s$ & $1.74(-4)$ & 3.84 & 36.06 & -0.97 & 1 \\
\hline$P^{+3}$ & ${ }^{a} 3 \mathrm{~s} 3 \mathrm{p}^{2}{ }^{2} \mathrm{D}$ & $9.46(-2)$ & $-5.58(-2)$ & 0.77 & -6.43 & 1 \\
\hline \multirow[t]{5}{*}{$P^{+4}$} & Total & 5.37 & 0.47 & 2.21 & -8.52 & 1 \\
\hline & ${ }^{a} 3 \mathrm{p}^{2}{ }^{1} \mathrm{D}$ & $6.80(-1)$ & -0.12 & 1.24 & -5.34 & \\
\hline & $3 \mathrm{~s} 3 \mathrm{~d}^{1} \mathrm{D}$ & $4.60(-1)$ & 0.70 & -0.88 & -0.72 & \\
\hline & $3 s 4 s^{3} S$ & 6.38 & $8.06(-2)$ & -0.90 & -0.49 & \\
\hline & $3 s 4 s^{1} S$ & 1.99 & $1.54(-2)$ & -0.61 & -0.68 & \\
\hline $\mathrm{Cl}^{+2}$ & ${ }^{b}$ Total & $1.00(-5)$ & 0.00 & 0.00 & 0.00 & 2 \\
\hline \multirow[t]{4}{*}{$\mathrm{Cl}^{+3}$} & Total & 1.88 & 0.32 & 1.77 & -5.70 & 2 \\
\hline & ${ }^{a} 3 \mathrm{~s} 3 \mathrm{p}^{4}{ }^{4} \mathrm{P}$ & $7.59(-1)$ & 0.44 & 3.10 & -7.53 & \\
\hline & $3 s^{2} 3 p^{2}\left({ }^{3} P\right) 3 d{ }^{4} D$ & $3.76(-3)$ & 3.29 & 14.86 & -0.97 & \\
\hline & $3 s^{2} 3 p^{2}\left({ }^{3} P\right) 4 s^{4} p$ & $9.59(-1)$ & $3.46(-2)$ & 0.20 & -11.13 & \\
\hline \multirow[t]{4}{*}{$\mathrm{Cl}^{+4}$} & Total & 7.27 & 0.29 & 1.04 & -10.14 & 2 \\
\hline & ${ }^{a} 3 \mathrm{~s} 3 \mathrm{p}^{3}{ }^{1} \mathrm{P}^{0}$ & $7.50(-1)$ & $-9.92(-2)$ & 1.36 & -5.52 & \\
\hline & $3 s^{2} 3 p\left({ }^{2} P^{0}\right) 4 p{ }^{3} D$ & 5.68 & 0.12 & -0.67 & -0.72 & \\
\hline & $3 s^{2} 3 p\left({ }^{2} p^{0}\right) 4 p{ }^{3} p$ & 3.80 & $-1.75(-2)$ & -0.58 & -0.67 & \\
\hline $\mathrm{K}^{+2}$ & ${ }^{b}$ Total & $1.00(-5)$ & 0.00 & 0.00 & 0.00 & 3 \\
\hline \multirow[t]{4}{*}{$\mathrm{K}^{+3}$} & Total & 4.76 & 0.44 & -0.56 & -0.88 & 3 \\
\hline & $3 s^{2} 3 p^{4}\left({ }^{3} P\right) 4 s^{4} P$ & 1.83 & 0.77 & -0.74 & -2.64 & \\
\hline & $3 s^{2} 3 p^{4}\left({ }^{3} P\right) 4 s^{2} p$ & 1.85 & 0.34 & -0.35 & -2.58 & \\
\hline & $3 s^{2} 3 p^{4}\left({ }^{1} D\right) 4 s^{2} D$ & $7.89(-2)$ & $3.36(-3)$ & 0.18 & -7.80 & \\
\hline${ }^{d} \mathrm{~K}^{+4}$ & ${ }^{b}$ Total & $1.00(-5)$ & 0.00 & 0.00 & 0.00 & 3 \\
\hline \multirow[t]{3}{*}{$\mathrm{Sc}^{+3}$} & Total & $7.22(-3)$ & 2.34 & 411.50 & -13.24 & 3 \\
\hline & $3 p^{6}\left({ }^{1} S\right) 4 s^{2} S$ & $2.84(-4)$ & 3.88 & 22.91 & -0.62 & \\
\hline & $3 p^{6}\left({ }^{1} s\right) 4 p{ }^{2} p^{0}$ & $3.45(-3)$ & $-5.04(-3)$ & 0.11 & -9.30 & \\
\hline \multirow[t]{5}{*}{${ }^{c} \mathrm{Sc}^{+4}$} & Total & $1.20(-1)$ & 1.48 & 4.00 & -9.33 & 3 \\
\hline & $3 s^{2} 3 p^{5} 4 p^{3} p$ & $3.72(-3)$ & 2.81 & 2.84 & -0.60 & \\
\hline & $3 s^{2} 3 p^{5} 4 p^{1} D$ & $2.98(-3)$ & 2.68 & 2.84 & -0.61 & \\
\hline & $3 s^{2} 3 p^{5} 4 p^{1} S$ & $1.70(-1)$ & 0.65 & -0.88 & -0.69 & \\
\hline & $3 s^{2} 3 p^{5} 4 d^{3} p^{0}$ & $1.95(-3)$ & $-8.87(-3)$ & 0.16 & -7.37 & \\
\hline \multirow[t]{4}{*}{$\mathrm{Ti}^{+3}$} & Total & $6.34(-1)$ & $6.87(-3)$ & 0.18 & -8.04 & 3 \\
\hline & $3 d 4 p{ }^{1} D^{0}$ & $1.80(-1)$ & $1.91(-2)$ & 0.20 & -9.21 & \\
\hline & $3 d 4 p{ }^{3} D^{0}$ & $2.23(-1)$ & $3.93(-3)$ & 0.19 & -8.29 & \\
\hline & $3 d 4 p{ }^{3} F^{0}$ & $2.10(-1)$ & $5.33(-5)$ & 0.18 & -7.99 & \\
\hline \multirow[t]{3}{*}{$\mathrm{Ti}^{+4}$} & Total & $4.37(-3)$ & 1.25 & 40.02 & -8.05 & 3 \\
\hline & $3 p^{6} 4 p^{2} p^{0}$ & $2.73(-4)$ & 3.44 & 880.68 & -21.66 & \\
\hline & $3 p^{6} 4 d^{2} D$ & $4.16(-3)$ & $-8.26(-3)$ & 0.18 & -7.12 & \\
\hline $\mathrm{V}^{+2}$ & ${ }^{b}$ Total & $1.00(-5)$ & 0.00 & 0.00 & 0.00 & 3 \\
\hline \multirow[t]{5}{*}{$v^{+3}$} & Total & 5.12 & $-2.18(-2)$ & -0.24 & -0.83 & 3 \\
\hline & $3 d^{2}\left({ }^{3} F\right) 4 p z^{4} G^{0}$ & 2.09 & $-9.70(-4)$ & -0.26 & -0.95 & \\
\hline & $3 d^{2}\left({ }^{3} F\right) 4 p z^{4} F^{0}$ & 1.42 & $-3.44(-2)$ & -0.28 & -0.85 & \\
\hline & $3 d^{2}\left({ }^{3} F\right) 4 p z^{2} F^{0}$ & $4.75(-1)$ & $4.28(-2)$ & 0.21 & -12.38 & \\
\hline & $3 d^{2}\left({ }^{3} F\right) 4 p{ }^{4} D^{0}$ & $5.54(-1)$ & $2.78(-2)$ & 0.19 & -9.29 & \\
\hline \multirow[t]{4}{*}{${ }^{c} \mathrm{~V}^{+4}$} & Total & $1.96(-1)$ & $-8.53(-3)$ & 0.28 & -6.46 & 3 \\
\hline & $3 d 4 d{ }^{1} F$ & $3.47(-2)$ & $-9.87(-3)$ & 0.31 & -7.18 & \\
\hline & $3 d 4 d{ }^{3} \mathrm{D}$ & $8.47(-2)$ & $-1.11(-2)$ & 0.28 & -7.05 & \\
\hline & $3 d 4 d{ }^{3} G$ & $5.83(-2)$ & $-1.03(-2)$ & 0.28 & -7.13 & \\
\hline $\mathrm{Cr}^{+2}$ & $3 d^{5} a^{6} S$ & $5.27(-1)$ & 0.61 & -0.89 & -3.56 & 3 \\
\hline \multirow[t]{7}{*}{${ }^{c} \mathrm{Cr}^{+3}$} & Total & 10.90 & 0.24 & 0.26 & -11.94 & 3 \\
\hline & $3 d^{3}\left({ }^{2} F\right) 4 s^{3} F$ & $3.04(-1)$ & 1.15 & -0.99 & -1.63 & \\
\hline & $3 d^{3}\left({ }^{4} F\right) 4 p^{5} G^{0}$ & 3.48 & 0.26 & -0.27 & -2.25 & \\
\hline & $3 d^{3}\left({ }^{4} F\right) 4 p{ }^{5} F^{0}$ & 2.47 & 0.13 & -0.18 & -1.39 & \\
\hline & $3 d^{3}\left({ }^{4} F\right) 4 p{ }^{5} D^{0}$ & 2.15 & 0.13 & -0.22 & -1.47 & \\
\hline & $3 d^{3}\left({ }^{4} F\right) 4 p{ }^{3} D^{0}$ & 1.21 & $9.81(-2)$ & -0.22 & -1.35 & \\
\hline & $3 d^{3}\left({ }^{4} F\right) 4 p{ }^{3} G^{0}$ & 1.00 & $-6.41(-3)$ & -0.23 & -0.87 & \\
\hline \multirow[t]{6}{*}{${ }^{c} \mathrm{Cr}^{+4}$} & Total & 1.18 & 0.20 & 0.77 & -7.09 & 3 \\
\hline & $3 d^{2}\left({ }^{1} S\right) 4 p{ }^{2} P^{0}$ & $7.31(-1)$ & 0.12 & -0.74 & -0.67 & \\
\hline & $3 d^{2}\left({ }^{3} F\right) 4 d^{4} G$ & $2.21(-1)$ & $-3.68(-3)$ & 0.34 & -7.01 & \\
\hline & $3 d^{2}\left({ }^{3} F\right) 4 d^{2} F$ & $1.21(-1)$ & $-6.99(-3)$ & 0.32 & -7.12 & \\
\hline & $3 d^{2}\left({ }^{3} F\right) 4 d{ }^{4} H$ & $2.02(-1)$ & $-3.96(-3)$ & 0.34 & -6.75 & \\
\hline & $3 d^{2}\left({ }^{3} F\right) 4 d{ }^{4} D$ & $1.11(-1)$ & $-7.76(-3)$ & 0.33 & -7.96 & \\
\hline $\mathrm{Mn}^{+2}$ & $3 d^{5}\left({ }^{6} S\right) 4 s a^{7} S$ & $1.65(-1)$ & $6.80(-3)$ & $6.44(-2)$ & -9.70 & 3 \\
\hline${ }^{c} \mathrm{Mn}^{+3}$ & Total & 14.20 & 0.34 & -0.41 & -1.19 & 3 \\
\hline & $3 d^{4}\left({ }^{5} D\right) 4 p z^{6} F^{0}$ & 1.89 & 0.71 & -0.69 & -2.74 & \\
\hline & $3 d^{4}\left({ }^{5} D\right) 4 p z^{6} P^{0}$ & 1.39 & 0.62 & -0.61 & -2.86 & \\
\hline & $3 d^{4}\left({ }^{5} D\right) 4 p z^{6} D^{0}$ & 2.53 & 0.41 & -0.43 & -2.65 & \\
\hline
\end{tabular}


TABLE 2-Continued

\begin{tabular}{|c|c|c|c|c|c|c|}
\hline Ion & Level & $\mathrm{a}\left(10^{-9} \mathrm{~cm}^{3} / \mathrm{s}\right)$ & b & c & d & Ref. \\
\hline & $3 d^{4}\left({ }^{3} F 1\right) 4 s c^{4} F$ & 1.79 & 0.31 & -0.32 & -2.48 & \\
\hline & $3 d^{4}\left({ }^{5} D\right) 4 p z^{4} F^{0}$ & 2.20 & 0.24 & -0.25 & -2.21 & \\
\hline & $3 d^{4}\left({ }^{5} D\right) 4 p z^{4} D^{0}$ & 1.01 & $1.58(-2)$ & -0.23 & -0.91 & \\
\hline \multirow[t]{4}{*}{${ }^{d} \mathrm{Mn}^{+4}$} & Total & $4.43(-1)$ & 0.91 & 10.76 & -7.49 & 3 \\
\hline & $3 d^{3}\left({ }^{2} F\right) 4 p w^{3} F^{0}$ & $5.58(-2)$ & 1.50 & -0.91 & -1.18 & \\
\hline & $3 d^{3}\left({ }^{2} F\right) 4 p w^{3} G^{0}$ & $1.88(-1)$ & 1.15 & -0.89 & -0.97 & \\
\hline & $3 d^{3}\left({ }^{2} F\right) 4 p e^{5} H$ & $2.81(-1)$ & $-2.87(-3)$ & 0.35 & -7.19 & \\
\hline \multirow[t]{6}{*}{${ }^{c} \mathrm{Fe}^{+4}$} & Total & 14.60 & $3.57(-2)$ & -0.92 & -0.37 & 3 \\
\hline & $3 d^{4}\left({ }^{3} F 1\right) 4 p{ }^{4} F^{0}$ & 1.82 & 0.35 & -0.89 & -0.57 & \\
\hline & $3 d^{4}\left({ }^{3} P 1\right) 4 p{ }^{4} P^{0}$ & 1.35 & 0.26 & -0.90 & -0.54 & \\
\hline & $3 d^{4}\left({ }^{3} P 1\right) 4 p{ }^{4} D^{0}$ & 1.85 & 0.25 & -0.90 & -0.53 & \\
\hline & $3 d^{4}\left({ }^{3} F 1\right) 4 p{ }^{4} G^{0}$ & 2.58 & 0.10 & -0.90 & -0.49 & \\
\hline & $3 d^{4}\left({ }^{3} F 1\right) 4 p{ }^{4} D^{0}$ & 2.65 & $4.95(-2)$ & -0.70 & -0.68 & \\
\hline \multirow[t]{3}{*}{$\mathrm{Co}^{+2}$} & Total & 5.30 & 0.24 & -0.91 & -0.47 & 3 \\
\hline & $3 d^{7}\left({ }^{4} F\right) 4 s$ a ${ }^{5} F$ & 2.03 & 0.76 & -0.99 & -3.13 & \\
\hline & $3 d^{7}\left({ }^{4} F\right) 4 s b^{3} F$ & $3.41(-1)$ & $1.51(-2)$ & $-4.70(-2)$ & -1.33 & \\
\hline \multirow[t]{10}{*}{${ }^{c} \mathrm{Co}^{+3}$} & Total & 3.26 & 0.87 & 2.85 & -9.23 & 3 \\
\hline & $3 d^{6}\left({ }^{5} D\right) 4 p z^{6} F^{0}$ & $4.61(-2)$ & 2.52 & 8.40 & -0.96 & \\
\hline & $3 d^{6}\left({ }^{5} D\right) 4 p z^{6} p^{0}$ & $3.63(-1)$ & 1.11 & -0.96 & -1.98 & \\
\hline & $3 d^{6}\left({ }^{5} D\right) 4 p z^{4} D^{0}$ & $4.87(-1)$ & 0.98 & -0.89 & -2.26 & \\
\hline & $3 d^{6}\left({ }^{5} D\right) 4 p z^{4} F^{0}$ & $7.29(-1)$ & 0.93 & -0.85 & -2.44 & \\
\hline & $3 d^{6}\left({ }^{5} D\right) 4 p z^{4} p^{0}$ & $9.53(-1)$ & 0.60 & -0.61 & -2.74 & \\
\hline & $3 d^{6}\left({ }^{3} H\right) 4 p z^{4} G^{0}$ & $1.63(-1)$ & $5.35(-3)$ & 0.17 & -8.30 & \\
\hline & $3 d^{6}\left(a^{3} p\right) 4 p y^{4} p^{0}$ & $1.24(-1)$ & $7.06(-3)$ & 0.17 & -7.45 & \\
\hline & $3 d^{6}\left({ }^{3} H\right) 4 p^{4} I^{0}$ & $1.28(-1)$ & $6.82(-3)$ & 0.19 & -7.90 & \\
\hline & $3 d^{6}\left({ }^{3} H\right) 4 p^{4} H^{0}$ & $1.13(-1)$ & $1.40(-4)$ & 0.16 & -6.90 & \\
\hline $\mathrm{Co}^{+4}$ & $3 d^{5}\left({ }^{4} F\right) 4 p^{5} F^{0}$ & 1.03 & 0.58 & -0.89 & -0.66 & 3 \\
\hline \multirow[t]{5}{*}{${ }^{c} \mathrm{Ni}+3$} & Total & 9.73 & 0.35 & 0.90 & -5.33 & 3 \\
\hline & $3 d^{7}\left({ }^{4} P\right) 4 p{ }^{5} D^{0}$ & 2.32 & 0.19 & -0.20 & -1.78 & \\
\hline & $3 d^{7}\left({ }^{2} G\right) 4 p^{3} H^{0}$ & 1.37 & $7.50(-2)$ & -0.23 & -1.24 & \\
\hline & $3 d^{7}\left({ }^{2} G\right) 4 p{ }^{3} F^{0}$ & 1.17 & $4.43(-2)$ & -0.21 & -1.01 & \\
\hline & $3 d^{7}\left({ }^{2} G\right) 4 p^{3} G^{0}$ & 1.04 & $-6.41(-3)$ & -0.24 & -0.89 & \\
\hline \multirow[t]{4}{*}{${ }^{c} \mathrm{Ni}^{+4}$} & Total & 6.14 & 0.25 & -0.91 & -0.42 & 3 \\
\hline & $3 d^{6}\left({ }^{3} F 1\right) 4 p{ }^{4} G^{0}$ & $8.03(-1)$ & 0.60 & -0.89 & -0.60 & \\
\hline & $3 d^{6}\left({ }^{3} P 1\right) 4 p{ }^{4} P^{0}$ & 1.34 & 0.27 & -0.90 & -0.53 & \\
\hline & $3 d^{6}\left({ }^{3} F 1\right) 4 p{ }^{4} F^{0}$ & 2.92 & 0.15 & -0.90 & -0.50 & \\
\hline $\mathrm{Cu}^{+2}$ & $3 d^{9}\left({ }^{2} D\right) 4 s^{1} D$ & $1.47(-3)$ & 3.51 & 23.91 & -0.93 & 4 \\
\hline \multirow[t]{7}{*}{${ }^{c} \mathrm{Cu}^{+3}$} & Total & 9.26 & 0.37 & 0.40 & -10.73 & 4 \\
\hline & $3 d^{8}\left({ }^{1} D\right) 4 p{ }^{2} F^{0}$ & 1.32 & 0.52 & -0.53 & -2.74 & \\
\hline & $3 d^{8}\left({ }^{1} D\right) 4 p^{2} D^{0}$ & 1.21 & 0.44 & -0.46 & -2.72 & \\
\hline & $3 d^{8}\left({ }^{3} P\right) 4 p{ }^{4} D^{0}$ & 2.61 & 0.23 & -0.25 & -1.95 & \\
\hline & $3 d^{8}\left({ }^{3} P\right) 4 p^{2} D^{0}$ & 1.12 & 0.13 & -0.19 & -1.41 & \\
\hline & $3 d^{8}\left({ }^{1} G\right) 4 p^{2} H^{0}$ & $8.53(-1)$ & $1.60(-3)$ & -0.24 & -0.92 & \\
\hline & $3 d^{8}\left({ }^{3} P\right) 4 p{ }^{2} F^{0}$ & $6.54(-1)$ & $-2.64(-2)$ & -0.24 & -0.85 & \\
\hline \multirow[t]{7}{*}{${ }^{c} \mathrm{Cu}^{+4}$} & Total & 11.59 & 0.20 & 0.80 & -6.62 & 4 \\
\hline & $3 d^{7}\left({ }^{2} D 1\right) 4 p{ }^{3} F^{0}$ & $9.81(-1)$ & 0.50 & -0.89 & -0.63 & \\
\hline & $3 d^{7}\left({ }^{2} D 1\right) 4 p^{3} D^{0}$ & 2.08 & 0.12 & -0.81 & -0.62 & \\
\hline & $3 d^{7}\left({ }^{4} F\right) 4 d^{5} F$ & 2.39 & 0.11 & 0.42 & -9.50 & \\
\hline & $3 d^{7}\left({ }^{4} F\right) 4 d^{5} G$ & 1.62 & $7.21(-2)$ & 0.39 & -8.53 & \\
\hline & $3 d^{7}\left({ }^{4} F\right) 4 d^{5} D$ & 1.07 & $7.77(-2)$ & 0.41 & -8.05 & \\
\hline & $3 d^{7}\left({ }^{4} F\right) 4 d^{5} H$ & 1.61 & $5.75(-2)$ & 0.41 & -8.42 & \\
\hline $\mathrm{Zn}^{+2}$ & ${ }^{b}$ Total & $1.00(-5)$ & 0.00 & 0.00 & 0.00 & 2 \\
\hline \multirow[t]{5}{*}{${ }^{d} \mathrm{Zn}^{+3}$} & Total & $6.96(-4)$ & 4.24 & 26.06 & -1.24 & 2 \\
\hline & $3 d^{9}\left({ }^{2} D\right) 4 p^{3} D^{0}$ & $1.61(-4)$ & 4.48 & 22.75 & -1.21 & \\
\hline & $3 d^{9}\left({ }^{2} D\right) 4 p{ }^{1} F^{0}$ & $8.43(-5)$ & 4.50 & 30.64 & -1.27 & \\
\hline & $3 d^{9}\left({ }^{2} D\right) 4 p{ }^{1} P^{0}$ & $1.17(-4)$ & 3.99 & 28.36 & -0.93 & \\
\hline & $3 d^{9}\left({ }^{2} D\right) 4 p^{1} D^{0}$ & $2.53(-4)$ & 3.91 & 24.07 & -1.00 & \\
\hline${ }^{d} \mathrm{Zn}^{+4}$ & $3 d^{8}\left({ }^{1} S\right) 4 p^{2} P^{0}$ & $1.33(-2)$ & 1.56 & -0.92 & -1.20 & 5 \\
\hline
\end{tabular}

Nork- The notation $a(b)$ here means $a \times 10^{b}$.

- Type II reactions; see text.

b Radiative charge transfer may be the most rapid mechanism.

c Result may be overestimated due to several channels having the same symmetry.

d See text.

ReFERENCES.- (1) Martin, Zalubas, \& Musgrove 1985; (2) Moore 1971; (3) Sugar \& Corliss 1985; (4) Sugar \& Musgrove 1990; (5) VanKleef, Joshi, \& Barakat 1984. 
TABLE 3

Charge Transfer Ionization Rates

\begin{tabular}{|c|c|c|c|c|c|c|}
\hline Ion & $\begin{array}{c}a \\
\left(10^{-9} \mathrm{~cm}^{3} \mathrm{~s}^{-1}\right)\end{array}$ & $b$ & $c$ & $d$ & $\begin{array}{c}\text { Temperature } \\
\text { Range } \\
\text { (K) }\end{array}$ & $\begin{array}{c}\Delta E / k \\
\left(10^{4} \mathrm{~K}\right)\end{array}$ \\
\hline $\mathrm{Li}^{\mathbf{0} \mathbf{a}}$ & $2.81(-3)$ & 2.00 & 221.36 & -47.64 & $1(2)-1(4)$ & 0.0 \\
\hline & $1.00(-5)$ & 0.00 & 0.00 & 0.00 & $1(3)-1(4)$ & 0.0 \\
\hline $\mathrm{N}^{0}$. & $4.55(-3)$ & -0.29 & -0.92 & -8.38 & $1(2)-5(4)$ & 1.086 \\
\hline $\mathrm{O}^{0} \ldots \ldots$ & $7.40(-2)$ & 0.47 & 24.37 & -0.74 & $1(1)-1(4)$ & 0.023 \\
\hline $\mathrm{Mg}^{\mathrm{Ob}} \ldots \ldots$ & $9.76(-3)$ & 3.14 & 55.54 & -1.12 & $5(3)-3(4)$ & 0.0 \\
\hline $\mathrm{Mg}^{+} \ldots \ldots$ & $7.60(-5)$ & 0.00 & -1.97 & -4.32 & $1(4)-3(5)$ & 1.670 \\
\hline $\mathrm{Si}^{+} \ldots \ldots \ldots$ & $4.10(-1)$ & 0.24 & 3.17 & $4.18(-3)$ & $5(3)-1(6)$ & 3.178 \\
\hline $\mathbf{S}^{0} \ldots \ldots \ldots$ & $1.00(-5)$ & 0.00 & 0.00 & 0.00 & $1(3)-1(4)$ & 0.0 \\
\hline $\mathrm{Cr}^{+} \ldots \ldots$ & 4.39 & 0.61 & -0.89 & -3.56 & $1(3)-3(4)$ & 3.349 \\
\hline $\mathrm{Mn}^{+} \ldots \ldots$ & $2.83(-1)$ & $6.80(-3)$ & $6.44(-2)$ & -9.70 & $1(3)-3(4)$ & 2.368 \\
\hline $\mathrm{Fe}^{+} \ldots \ldots \ldots$ & 2.10 & $7.72(-2)$ & -0.41 & -7.31 & $1(4)-1(5)$ & 3.005 \\
\hline $\mathrm{Co}^{+} \ldots \ldots$ & $1.20(-2)$ & 3.49 & 24.41 & -1.26 & $1(3)-3(4)$ & 4.044 \\
\hline
\end{tabular}

NoTE.-The notation $a(b)$ here means $a \times 10^{b}$.

${ }^{a}$ Data from Kimura, Dutta, \& Shimakura (1994) and Stancil \& Zygleman (1995).

${ }^{b}$ Data from Allan et al. (1988).

TABLE 4

ENDOTHERMIC REACTIONS

\begin{tabular}{cc}
\hline \hline Ion & $\begin{array}{c}\Delta E \\
(\mathrm{eV})\end{array}$ \\
\hline $\mathrm{Ca}^{+2} \ldots \ldots$ & -1.73 \\
$\mathrm{Sc}^{+2} \ldots \ldots$ & -0.80 \\
$\mathrm{Ti}^{+2} \ldots \ldots$ & -0.02 \\
\hline
\end{tabular}

parent ion) $\mathrm{F}^{+3}, \mathrm{Ne}^{+4}, \mathrm{Mg}^{+3}, \mathrm{Mg}^{+4}, \mathrm{P}^{+4}, \mathrm{~S}^{+4}, \mathrm{Cl}^{+4}$, $\mathrm{Ar}^{+4}, \mathrm{Cr}^{+3}, \mathrm{Mn}^{+3}, \mathrm{Fe}^{+4}, \mathrm{Ni}^{+3}, \mathrm{Cu}^{+3}$, and $\mathrm{Cu}^{+4}$. Only $\mathrm{L}-\mathrm{Z}$ rates are currently available for these reactions, all of which are predicted to be large (several times $10^{-9} \mathrm{~cm}^{3} \mathrm{~s}^{-1}$ at $10^{4}$
$\mathrm{K})$. In addition, based on the discussion in the previous section, $\mathrm{O}^{+}$should also be examined at higher temperatures.

A code which calculates the total rate coefficients presented in this paper can be obtained from the authors on request. The code and the tables are also available on the World Wide Web at URL http://www.pa.uky.edu/ kingdon/ct.html.

We thank D. Schultz at Oak Ridge National Laboratory for providing a bibliography of the reactions considered in this paper, and P. C. Stancil for valuable comments. This work was supported by NSF grant 93-19034 and NASA grant NAGW-3315.

\section{REFERENCES}

Allan, R. J., Clegg, R. E. S., Dickinson, A. S., \& Flower, D. R. 1988, MNRAS, 235, 1245

Arnaud, M. \& Rothenflug R. 1985, A\&AS, 60, 425(AR)

Berrington, K. A., Burke, P. G., Butler, K., Seaton, M. J., Storey, P. J., Taylor, K. T., \& Yu, Y. 1987, J. Phys. B; 20, 6379

Bienstock, S. 1983, Comput. Phys. Commun., 29, 333

Butler, S. E., \& Dalgarno, A. 1979, ApJ, 234, 765 . 1980a, ApJ, 241, 838 (BD) 1980b, A\&A, 85, 144

Butler, S. E., Guberman, S. L., \& Dalgarno, A. 1977, Phys. Rev. A, 16, 500

Butler, S. E., Heil, T. G., \& Dalgarno, A. 1980, ApJ, 241, 442

Chambaud, G., Launay, J. M., Levy, B., Millie, P., Roueff, E., \& Tran Minh, F. 1980, J. Phys. B, 13, 4205

Dalgarno, A. 1954, Proc. Phys. Soc. London, 67, 1010

Field, G. B., \& Steigman, G. 1971, ApJ, 166, 59 Gargaud, M., Hanssen, J., McCarroll, R., \& Valiron, P. 1981, J. Phys. B, 14,

Gargaud, M., McCarroll, R., \& Opradolce, L. 1989, A\&A, 208, 251

Gargaud, M., McCarroll, R., \& Valiron, P. 1982, A\&A, 106, 197

Herrero, B., Cooper, I. L., Dickinson, A. S., \& Flower, D. R. 1995a, J. Phys. B, 28, 711

1995b, J. Phys. B, 28, 4607

Honvault, P., Gargaud, M., Bacchus-Montabonel, M. C., \& McCarroll, R. 1995, A\&Ä, 302,931
Hummer, D. G., Berrington, K. A., Eissner, W. Pradhan, A. K., Saraph, H. E., \& Tully, J. A. 1993, A\&A, 279, 298

Kimura, M., Dutta, C. M., \& Shimakura, N. 1994, ApJ, 430, 435

Kingdon, J. B. 1995, MNRAS, 274, 425

Kingdon, J., Ferland, G. J., \& Feibelman, W. A. 1995, ApJ, 439, 793

Martin, W. C., Zalubas, R., \& Musgrove, A. 1985, J. Phys. Chem. Ref. Data, 14,751

Moore, C. E. 1971, Atomic Energy Levels (NBS Circ. 467)

Neufeld, D. A. 1984, Harvard Research Exam

Neufeld, D. A., \& Dalgarno, A. 1987, Phys. Rev. A, 35, 3142

Seaton, M. J. 1987, J. Phys. B, 20, 6363

Stancil, P. C., \& Zygelman, B. 1995, in preparation

Stancil, P. C., Zygelman, B., Clarke, N. J., \& Cooper, D. L. 1995, in preparation

Sugar, J., \& Corliss, C. 1985, J. Phys. Chem. Ref. Data, 14, Suppl. 2

Sugar, J., \& Musgrove, A. 1990, J. Phys. Chem. Ref. Data, 19, 527

Swartz, D. A. 1994, ApJ, 428, 267

VanKleef, Th. A. M., Joshi, Y. N., \& Barakat, M. 1984, Phys. Scr., 29, 216

Verner, D. A., Ferland, G. J., Korista, K. T., \& Yakovlov, D. G. 1996, ApJ, in press

Verner, D. A \& Yakovlev, D. G. 1995, A\&AS, 109, 125

West, B. W., Lane, N. F., \& Cohen, J. S. 1982, Phys. Rev. A, 26, 3164

Zygelman, B., Dalgarno, A., Kimura, M., \& Lane, N. F. 1989, Phys. Rev. A, 40,2340 